This is the accepted version of the manuscript published by Landscape Research

Full reference: Costa, S., \& Coles, R. (2019). The self-narrated walk. A user-led method to research people's experiences in urban landscapes. Landscape Research, 44(5), 526-540.

https://doi.org/10.1080/01426397.2018.1467004

Published online in June 2018

To link to this article: https://doi.org/10.1080/01426397.2018.1467004

Funding: This work was supported by Portuguese Foundation for Science and Technology (Fundação para a Ciência e Tecnologia (QREN - POPH - Tipologia 4.1-Formação Avançada, comparticipado pelo Fundo Social Europeu e por fundos nacionais do MCTES), under the [Grant number SFRH/BD/65438/2009].

\title{
The Self-Narrated Walking. A User-led Method to Research People's Experiences in Urban Landscapes
}

\section{Sandra Costa \& Richard Coles}

Birmingham School of Architecture and Design, Birmingham City University, Birmingham, UK

\section{Contact author: Sandra.costa@bcu.ac.uk}

\begin{abstract}
Walking interviews and mobile ways of engaging participants in research have recently begun to emerge as methods to collect data that tries to understand people's relationships with places. This work explores the self-narrated walk as a method to research people's encounters and interactions with the landscape and their associated meanings and values. We address the method by explaining and examining how it has been designed, implemented and experienced by participants who engaged in a set of environmental immersive encounters in urban green landscapes. The findings show that this approach offers the user perspective, and facilitates in situ, mobile and in-themoment, detailed, complex personal descriptions and meanings into the mechanisms behind physical and emotional person-place interactions. Additionally, they suggest that the method is excellent to empower participants, to stimulate engagement with
\end{abstract}


places and to capture simultaneously different data sets. Finally, we discuss potential implications for landscape research and for the design process.

Keywords: walking and talking, user experience, person-place interactions, green spaces, mobile methods, narratives, GPS data.

\section{Introduction}

With this paper we want to draw attention to the importance of being in and making contact with the environment; of capturing the reality of the 'lived experience' and thus designing and adopting methods that enable sophisticated collection of data in ways that are capable of revealing the detailed perception of the environment.

Research into the perception of the landscape calls for approaches that are immersive, i.e. carried out in situ, in order to capture the 'lived in' experience of users (Pink 2007; Ward Thompson et al. 2010). While a diversity of methods has been used many of these are based on static views, practices using image-based models (e.g. photos, drawings, videotapes), or viewings from fixed points (Kaplan \& Kaplan 1989; Herzog et al. 2002; Hartig \& Staats 2004). Others use approaches based on numerical evaluation and rating scales which measure for example, physiological (Hartig et al. 2003) and emotional (Van den Berg et al. 2003) user responses. Such approaches have limitations in that, although they identify overall trends, they are very much detached from user-based lived experiences.

In this paper we intend to argue for a position that encourages the investigation of user experience, exploring a user-led method that specifically gives voice to users - the selfnarrated walk - to research people's encounters and interactions with the landscape, their associated meanings and values and thus contribute to the discussion regarding processes of engagement with places and nature. First, we set out the research context and discuss several concepts and approaches that put the person at the core of the experience and in contact with the environment. We also explore how these feed into methods that address walking and the use of user-based narratives to consider the design and implementation of the self-narrated walk, how it was experienced by the research participants, highlighting the key parameters and the type of environmental 
interactions involved during the experience. Finally, we demonstrate its relevance to landscape research and what the approach has to offer to the design process.

\section{Towards an Experiential Approach}

Heft (2010 p.14) points out that in static displays 'the perceiver is taken to be an observer of the environment layout standing apart from it while surveying its qualities or possibilities.'. His statement stresses the idea that environments cannot be fully perceived, experienced and assessed from detached points of view. Ward Thompson et al. (2010) emphasise that for the in depth exploration of places and people's experiences sensitive qualitative methods are required. Others stress the need to consider the body in motion and the kinaesthetic interaction inherent in the reality of moving through the landscape (Bannon 2011) and the total interaction of the body (Pink 2007).

Accordingly, phenomenological approaches form the base for studying how people make sense and experience the world (Willig 2001) and meanings of everyday life (VanderStoep \& Johnston 2009). Phenomenology starts from consciousness and structure of experiences which 'includes perception, imagination, thought, emotion, desire, feeling and other forms of inner experience' (Smith 2011). In this context, Leach (2005) suggests there has been a tendency to perceive space isolated from the body and its sensations, privileging the visual and weakening our understanding of space. Phenomenology 'calls for a heightened receptivity of all the senses' (Leach 2005, p.80). The notion of phenomenology has changed significantly since its founding by Husserl, moving from consciousness and its essential structures separated from the lived realm of experience, to actual lived experience (Seamon 2000). Martin Heidegger, highlighted the idea that people do not exist separate from the world and are intimately immersed in it (Seamon 2000). Merleau-Ponty (1995) gives theoretical foundation to address methods for researching people's experiences of the landscape by placing the body at the core of the experience as the interface for perception and stressing its motility qualities.

Berleant (2004) highlights the importance of physical presence in the environment, and of the context. When people are in contact with the environment as participants, being exposed to its qualities and possibilities (Berleant 2004), a new perspective is revealed: the experience becomes different, changeable, and contextual, being dependent on those factors and connections that are present, and contribute to create a unique personal, social, cultural and 
historical situation (Berleant 1992; Berleant 2010). At the core of the experience lies sensibility (Berleant 2010), and thus awareness of engagement of the full senses in environmental perception is essential (Berleant 1992; Leach 2005) in order to understand the complex person-environment interactions.

\section{Collecting narratives through landscape encounters}

Exploring narratives as a reliable form of data collection has been found to help improve methodologies that research person-place links (Coles \& Bussey 2000; Schroeder 2002; Costa et al. 2014; Coles et al. 2013). Narratives are most accepted and broadly defined as people's telling of stories about their living, and can articulate language, take a form textual or oral narratives (Murray 2003; Wiles et al. 2005), photo-diaries (Latham 2004) and walks with video (Pink 2007). The narrative form is also a mechanism of knowing, a way of reasoning and explaining the world by connecting and structuring sequences of events through stories and situations over time (Murray 2003; Wiles et al. 2005; Clandinin \& Connelly 2000). Narratives are particularly significant as a strategy for engaging with complex and intense emotional accounts (Wiles et al. 2005), crucial in the context of developing methods that lay stress on the affective/emotional aspects of the experience.

Self-narration uses the first person in a narrative, uncovering a 'self-perspective' and an interpretative construction of the experience. Wylie (2005) found, in narrating his own walking experience in a landscape on the South West Coast Path, that narratives are a method to describe and discuss affinities and detachments concerning the relation between the self and landscape in which movements, sensations, thoughts and encounters are extracted. Notwithstanding its role in shaping personal identities, the narration is also a negotiation of the links between people's personal narratives and their social context (see Murray 2003) and connects intimate details of experience to broader social and spatial relations (Potteiger \& Purinton 1998; Wiles et al. 2005).

\section{Walking and narratives as a way to enable contact with the environment}

Wunderlich (2008) defines walking as a kind of participation that elicits sensorial engagement and interaction with the landscape. Lund $(2012 ; 2005$, p.28) refers to a comprehensive kinaesthetic act that combines movement, 'postures, speeds, rhythms', the sensing body and landscape, being that the interaction between them shape each other. Many qualitative studies have included methods that are mobile-based and have combined walking 
and talking with the purpose to elicit a sense of connection with places (Ingold \& Vergunst 2008). Walking and talking methods include, for example, participatory video (Pink \& Mackley 2012; Pink 2007), go-along interviews (Carroll et al. 2013; Degen \& Rose 2012; Carpiano 2009), narratives of own walking practices (Wylie 2005; Lund 2012) and group narrated walks (Millman 2012).

Walking interviews have been used as a research method in which the researcher takes participants to the context and spatiality of the object actually being investigated (Jones et al. 2008) to explore environmental perception, everyday urban experience, and the relationship between spatial practices and social realms (see Kusenbach 2003; Carpiano 2009; Degen \& Rose 2012). Walking and talking is presented with several variations resulting from the ways interviews or routes are structured (Evans \& Jones 2011). As a result, different terms such as 'walking whilst talking' (Anderson 2004), 'go-along' (Carpiano 2009), 'walk-along' (Degen \& Rose 2012), 'the itinerary method' (Petiteau 2006) and 'the narrative in-real-time' (Miaux et al. 2010) emerged. Nevertheless, they are all based on the premise of a researcher walking alongside the participant interviewing him/her in the environment. Carpiano (2009) points out that these methods tend to help building rapport with participants, to increase collaboration, and to transfer power to the participant by minimising the usual power relations between the interviewer and interviewee that exist in traditional interviews. Several authors (Wylie 2005; Edensor 2000; Lund 2012) have reflected on narratives of their own walking experience exploring the relationship between landscape and self. These are mostly post-walking reflections and not fully narrated in real-time. Nonetheless, what is noteworthy is that these researchers actively explore personal reflections on embodiment and involvement with the landscape through walking and their experiential encounters.

Millman (2012) developed further the walking and talking technique, putting forward an approach incorporating real-time narratives conducted without the researcher's presence. In her approach a loose group of participants are left alone, within sight of one another, to experience and reflect on the experience of the landscape, talking aloud into an audio recorder. 


\section{The Self-Narrated Walk}

\section{Design strategy}

In developing the self-narrated walk as a method we argue for a position that values the study of user experience and explores processes of engagement with places and nature while enhancing ways that give voice to users. The self-narrated walk seeks to explore experiential rather than analytical approaches and thus it starts from five main premises: 1) it takes place in situ with the participant in contact with the environment; 2) the participant gives his/her own perspective; 3) the data collection occurs in real-time, in-the-moment or in the immediacy of the moment; 4) it occurs whilst walking; and 5) it moves away from static representations. Therefore, the self-narrated walk is defined as a method which permits direct engagement with the environment, enables people to know and make sense of experiences, and allows the recording of people's perceptions of their experiences in situ, in-movement and in-the-moment.

Through the use of complementary hand-held digital recording and tracking media, audio recorded narratives, photographs, movements and speed are captured without the researcher's presence to obtain real-time integrated data streams (Costa 2015). The approach asks users to narrate their journey as they negotiate/experience the environment, rather than standing apart observing. It expresses the meaning of the encounter, the immersion of the body and the interaction with the surrounding's unique qualities (see Berleant and Merleau-Ponty works), moving away from a static to a dynamic representation where the experience is presented through a personal account of experienced space and time (Costa 2015; Millman 2012; Coles et al. 2013).

\section{Methodological parameters}

The self-narrated walk collects personal narratives and allows, in a single walk, gathering different interactive data-sets (spoken narratives, GPS information and photographs) associated with one participant's walking journey (see Figure 1). [Figure 1 near here] We also conducted short post-walk interviews and collected reflective diaries. The post-walk interviews were intended to explore issues arising from the implementation of the selfnarrated walk (e.g. what it was like to perform the task, the handling of the equipment) and to further the understanding of the experience. Both post-walk interviews and 
diaries reinforced ideas and expanded, complemented and corroborated on the walking method; the diaries enabled the examination of regular, over time, reflective accounts of the experiences. Extracted quotes from both are also used later in this paper to illustrate aspects of the approach.

\section{Location}

The walks took place in two urban green spaces selected for their combination of landscape characteristics and range of different spaces and environments each having a discrete landscape identity, safety and availability of services, easy yet variable walking access, diversity of path structure (Coles \& Caserio 2004), specifically Serralves Park (PS), Portugal (see Andresen 2011), and Birmingham Botanical Gardens (BBG), UK (see Ballard 1983). These are designed urban green spaces which have the capacity to present participants with an on-site immersive experience, drawing upon an urban population as a visitor base, with well-established user/visitor groups, thus facilitating the selection of participants. Both offer a broad set of environments and opportunities for different modes of interactions and discovery which children and adults alike can explore.

\section{Participants and guidance}

Adult male and female participants were identified by means of a questionnaire targeting selected sites' users and also designed to assist in the identification of the walking route. Thirty participants divided into two groups were selected to undertake lone self-narrated walks. The BBG group was made of 16 individuals whereas the PS group was made of 14 . The two groups of participants showed slightly different trends in terms of age. The PS group was represented by younger participants with all except one being equal or under the age of 50 whereas in the BBG group half of the participants were over the age of 50.

The walks were GPS tracked, photographed and audio recorded. These took place between May 2012 and February 2013, to encompass at least two contrasting seasons to capture specificities, differences and similarities arising from the seasonal changes (Ward Thompson et al. 2010). All thirty participants took part in at least one self-narrated walk. Thirteen of these also participated in a second walk, making a total of forty-three walks.

All participants were informed about the procedures of the activity and timetable; at the gardens, participants were met individually and provided with guidance: 
Follow the route prescribed, although you are free to explore other places; take your time, you can walk, stop, sit down, and talk with other users if you feel like it; take pictures of your favourite or other places or experiences; relax and let yourself go; ... allow yourself to interact with the environment; You are free to talk about everything, including: your memories, thoughts, feelings, sensations, preferences, emotions, the physical (or other) characteristics of the place.

Instructions were given regarding handling the devices and participants were asked to keep the audio recording continuously running, and to photograph places and experiences that were of their interest.

A site map containing a prescribed route and direction based on favourite places derived from an initial questionnaire was presented and provided to participants before the walk. A predefined route gives basic structure and planning to the walk and allows covering a set of different fixed environments. Notwithstanding, it must also be flexible enough to encourage additional wandering and exploration of other areas, attractions, particularly meaningful places and connections which might be of participants' interest and expectation in order to reveal particularities of the experiential process. Thus, it was not contained by the path (see Ingold 2008). Participants were in control of their movement, following their own pace and time. Hence, the period of time to complete the walk was at the participant discretion taking between 20 and 75 minutes.

\section{Building up rapport and trust}

Scott (1984 cited in Shah 2004) emphasises the need to establish rapport and trust between researcher and participants, and argues that 'when people thought the interviewer less threatening they often felt more open about what they felt' (p. 122). Face-to-face meetings require special sensitivity because when participants notice themselves as vulnerable, marginalized and in a sensitive or delicate position they tend to be hesitant to share information (Adler \& Adler 2001).

First contacts are very important to achieve rapport. On the day of the walk activity, participants were invited for a coffee at the gardens' coffee shop or to sit at a location of their preference. Over the course of 15 minutes we sought to clarify any doubts, explain roles, and receive the signed consent form, but also to reassure/calm those participants who admitted experiencing an element of anxiety about the activity. 
We had a very relaxed talk before the walk so I felt no pressure about the project. [post-walk commentary, Mary]

This initial conversation enables participants to discern to what extent they will share personal information and help reducing the distance between participant and researcher (Adler \& Adler 2001; VanderStoep \& Johnston 2009). There were initially concerns regarding how participants would respond when asked to talk aloud in the form of monologue, their potential inhibition to share the experience in such a way, and the extent it would break the flow of the interaction. We believe that building rapport and trust with participants gives them a sense of permission to interact with and talk the landscape, thus being key to overcome concerns, get freed of fears, and reduce or eliminate reluctance to speak and potential withdrawal.

\section{Devices}

Audio recorder. To record the walking narratives, we made use of a pocket-sized, high quality, digital audio recorder, carried on their pockets with a small wired microphone clipped to the lapel. We were aware of the importance of creating an atmosphere as much as possible close to a regular walk in the gardens and to avoid any needless interference with the experience. The audio recorder captured participant's speech, their hesitations, pauses and silent moments, plus the distinctive 'contextual background sounds', 'contained noise' from the experienced landscape where the walks were taking place (e.g. children and adults' voices, running water, footsteps, birdsongs and wind) and 'external noise' from outside places (e.g. nearby busy roads, train, aerial traffic, and sirens).

GPS device. The GPS device used was provided with an incorporated camera facilitating the manoeuvre with one less piece of equipment and reinforcing the premise to eliminate all the unnecessary tools. In the self-narrated walk, the researcher is not accompanying the participant to take note of what they say (Jones et al. 2008; Evans \& Jones 2011), thus this is a powerful tool to track participants movements and speeds.

\section{Verbalising the experience}

Wylie (2005) argues that narrating own walking experience is a method of gathering the distinctive senses of the self and spatiality, and a way to describe affinities and detachments, the movements, sensations, thoughts and encounters. Engaging participants in such an introspective activity as the self-narrated walk and requesting them to verbalize and record 
their personal experiences in real-time was thought-provoking; it implies talking to oneself aloud in public. This contextual aspect may, however, have an element of influence on the walking dynamic. For example, one participant avoided a section of the BBG's Aviary as there were many children around and a few others commented on the suspicious and curious looks of other users towards them, suggesting that they were conscious of the task given.

Having the audio recorder as an intermediate, the researcher worked as an immediate, nonpresent, receiver of participants accounts. Many participants talked to, and gave indicators that they were conscious of, the researcher. For example, one participant highlighted that the photographs she was taking would better explain what she was feeling and seeing, and another one drew the researcher attention to the sound of running water:

I've just realized that this plane going by will probably be recorded as well as my voice, so this small waterfall I'm going to photograph will also be recorded. Can you hear it? It's definitely one of the things that make me feel better when I'm here... [self-narrated walk, Teresa]

The descriptions of the experience tend to be very thoughtful, precise, expressed in eloquent and rich language, and share characteristics of the place, interactions, personal stories and memories, emotions and preferences.

I really like to come here with my son (...), it is also one of children's preferred areas, because of this little maze (...) and sometimes it also makes me play and run through this area. (...) it brings [me] back to my childhood, to the mazes of organized gardens, (...) the nice little fountain, which I love to sit on and see these beautiful water lilies. Many times during my childhood I chose these places to be and to play... very pleasant with these flowers, these colours, these textures, with pine trees in the distance (...). Again the sound of our steps hitting these little stones is very nice (...). (...) I used to bring my little boy and feed him here... Here I could spend hours taking pictures and ... I feel (...) the smell of roses [self-narrated walk, Lara]

Thus, verbalising the experience whilst it was occurring enabled capturing, clarifying, and maintaining in-the-moment information and perceptions, which would have otherwise been lost in a post-walk interview.

Participants found in narrating the walk aloud a practise that made them more 'observant', a process of 'counselling', and a 'challenge' putting into words thoughts and feelings. Listening to their own voice made them more aware and reflective of self (e.g. their 
personality and personal life) and the surroundings, assisting in the process of making sense of the experience:

I have never narrated a walk before and I found the process unexpectedly interesting. It made me more observant (...), which in this instance I found enjoyable; and it also made me analyse my feelings. [post-walk commentary, Louise]

I think talking as you walk is a bit like the process of counselling, where you don't know what's in your brain - you can't work it out for yourself - until someone asks you a particular question. [post-walk commentary, Antony]

However, occasionally participants would favour walk silently and not hear their own voice, which is in itself indicative of purposeful interaction:

$\ldots$ it was so nice to walk in this path and I felt that if I would be alone, or even not alone,... with my boyfriend,... we would walk silently, because is just so beautiful. [post-walk commentary, Zelen]

\section{Walking alone}

Walking alone was crucial in maintaining participants focused on the task given and immersed in the environments, in following their own internal and external rhythms and flows, which allow for states of relaxation and support personal reflection (Millman 2012). It thus elicited strong person-place interactions and led to noticing aspects unnoticed before while walking with others during other visits. Additionally, the lone walk enabled the collection of responses without direct intervention resulting from either the company of the researcher or another participant:

...[it] Means that you enjoy the Botanical Gardens very differently when you go around it with children - don't usually go near the playground when I've not got kids with me. (...) Also, because you're family, time is spent talking as you walk along and I was aware that I've not taken in as much detail as I'd walked along as when on my own. [reflective diary, John]

Choosing which places to go while accompanied is a negotiated decision and involves time dedicated to others and less focus and awareness of the details of the environment. In many cases, going to the park/garden brings together the responsibility of having to watch out or care for others, but during a lone walk participants are allowed to create time for themselves and to immerse in the experience: 
Usually I come with the children, they are running around and I'm running behind them so I'm actually not enjoying as much as I would like to. (...) [self-narrated walk, Amira]

A key issue in walking alone is safety (Coles \& Caserio 2004). The question of safety regarding being alone was raised by one participant who throughout the walk went through a process of increasing the confidence realising safety was not an issue. The reason why safety was not a real concern among participants is that the selected landscapes are controlled and familiar environments and thus are perceived as safe (see Straathof 1993 in van den Berg 2003; Evenson et al. 2006). When the environment does not represent a threat, walking alone is an advantage as participants are more focussed on the task and more willing to share personal experiences and stories with the researcher. In our research the focus is on the individual and individual experiences and thus social interaction and co-experience are limited. Nonetheless, we appreciate that there is scope in the self-narrated walk to accommodate small groups, thus having the potential to activate somewhat different interactions.

\section{Mapping and photographing the experience}

The GPS device added extra layers of information allowing the overall mapping of the selfnarrated walk. Its use is an advantage in mapping the places, narratives and experiences, enabling representations of spatial patterns in time and space (Nielsen \& Hovgesen 2004; Evans \& Jones 2011; Jones et al. 2008) and tracking participants' movements (see Figure 2) while gathering additional quantitative data related to the walk such as pace/speed and stopping points (e.g. stopping was associated with certain types of interaction). Since the method is underpinned by lone walks, and the researcher is not accompanying the participant, without this tool it would be difficult to track participants' movements and to link their comments to places (Jones et al. 2008; Evans \& Jones 2011). That is, contextual statements such as 'from here I can see...' or 'this place here...', often heard during the walks, would be hard to link to a place.

[Figure 2 near here]

[Figure 3 near here]

Participants were asked to take photographs that represented and reflected aspects of the experience including both positive and negatives features of the environment. The participant-generated photographs show more than what is inherent to the content. They are contextual and the depiction goes beyond the visible, the colours, the shapes. One participant 
took a photo of the blue flowers of a catmint plant whilst remembering and describing an old episode of his toddler son's interactions with it. Thus, "what-is-not-visible" (Rose 2014), the meanings and the memories attached to a single photograph taken, is of great significance. Each person will make different judgements and attach different meanings to the same photograph taken by someone else (Millman 2013), as images are negotiable and open for interpretation. Thus, photographs give extended explanation and reinforce information difficult to capture with written or oral narratives, and provides a visual representation of other layers of the experience (see Figure 3).

Additionally, taking photographs is a mediator of the interaction between landscape/place and individual:

Lovely colours here. Lovely combination of colours with these... I've got to take a picture of these because these really are gorgeous all together and all the combination of colours... I just love that. Isn't that nice, the bright orangey yellow?... [self-narrated walk, John]

Meaning, that the camera was used as a means to draw closer, to observe, touch, reinforce and appreciate the elements of the landscape. The material produced can be a powerful medium to prompt further discussion and reflection (Rose 2014) on the walking journey.

\section{Specific interactions recorded by the self-narrated walking}

The method is able to capture in-the-moment experience between self and place. That is, the interactions and its mechanisms, the sequence of events and places where the interaction and the narrative occurs, the perceptions, preferences, memories, emotions and feelings. To give a sense of how a self-narrated walk unfolds, the following passage illustrates one participant's experience and sequence of steps within the Tropical Glasshouse:

John enters the Tropical Glasshouse and begins talking about what he sees and feels. He walks towards the pool and stands watching the koi carp fish swimming around. He immediately notices the warmth atmosphere, his glasses not steaming up for once, the relaxing feeling of that moment, and the quietness of the place resulting from the absence of people. He loves the place, except for the people 'feeling a need to throwing money into [the pool]', which irritates him a little. He refers to the diversity of the place throughout the year, the greenness, the lushness, and some of the plants, particularly the sensitive plant:

I love this place... There is a lot throughout the year (...). There is a particular plant, called a sensitive plant that I always love touching on the knuckle and watching the leaves react or 
shrivel up. I'm doing that now and it's really wonderful to watch how rapidly it reacts, it's really wonderful. I love the colours of the leaves, the varied colours in the veins and the pinks and reds and greens and shades of green. And the fronds of the leaves they've just been watered which is rather lovely. So there's drops of water which is super as the sun glimpses through. [self-narrated walk, John] (see Figure 4)

[Figure 4 near here]

The method captures spatial awareness and making sense of it. John is aware of his immediate surroundings, of their sensory qualities (e.g. the temperature, the sounds) and the place components (e.g. the pool, the plants, the colours). He walks slowly, he stops and he stands by the pool (GPS data) looking at the fish and touching the sensitive plant. He takes photos of these two moments (see Figure 4). Walking slowly allows taking in the surroundings, to increase bodily engagement by interacting with various elements of that place and to pay attention to the details. Because of his familiarity with the place ("I always love touching"), he is able to connect what he sees in that moment with what he expects to happen at other times of the year. He demonstrates his feelings - "I love this place"; I love the colours".

Therefore, the most primary interaction with the environment is people's own movements through the places - the kinaesthetic experience. This, then, allows for movements towards intense sensory engagement (Wunderlich 2008; Ingold 2004), or full body experiences of moving, feeling, viewing, touching, hearing and smelling, and the perception of qualities of place which prompt particular kinds of interaction (e.g. running leaves on the water, getting closer to the fish, touching plants), more specific, participative or introspective (e.g. silence, sharing of memories).

\section{Potential contribute of the self-narrated walking to the design process}

The practicality of the self-narrated walk method has further interest and implications for designers who need to understand the user experience but also the landscape/site dynamics. The development of the method to undertake our research suggests that part of this understanding requires proximity and engagement with the landscape and with the user, in order to acknowledge different perspectives of perception and feeling, to discover and to increase sensitivity to interactions, sensorial qualities as well as processes, structures, scenarios and narratives (Foxley \& Vogt 2010). 
With the growing awareness of the importance of contextual information in driving the design process (Visser et al. 2005), the self-narrated walk offers an opportunity for users and the different publics to become an active part of the design process, in particular, during the initial stage associated with site investigation and analysis. The user-centred approach that the self-narrated walk conveys has the potential to empower users and stakeholders towards revealing and unlocking responses and insights that are practical in the implementation of evidence-based ideas and thus having a role in co-designing of urban spaces. Therefore, the self-narrated walk connects users, as experts in their own experiences (Visser et al. 2005), to the multi-dimensions of a landscape, and utilises landscapes as a lab in order to understand practices, and the meanings and reasons behind individual experiences, providing insights to inform sensitive designs.

By stimulating movement, engagement and direct contact with places it enables those involved to promptly voice their preferences, emotions, memories, interactions, values (e.g. aesthetics), and the environmental characteristics, uncovering also those experiences that are beyond the visible (van Etteger 2016), ephemeral, transcendental and thus difficult to acknowledge. This experienced knowledge may be synthetized and translated into spatial principles, in order to underpin designs of places focused on the user experience, movement and sensory experiences as constructed by people's connections, senses, feelings and experiences in time (Riley 1998).

Many unique aspects that matter to the user are normally disregarded or given little consideration both in research and in the design process. One of the aspects that the method is able to reveal is the users' intentional silent moments and the contexts, mechanisms and places where these tend to occur, which may be able to impact on the design of places that favour personal reflection and more passive experiences/interactions. GPS recording the walking speed might uncover dynamics and reasons behind why people slow down, stop and interact with certain places while moving rapidly through others (Costa et al. 2015). Knowing what underpins experiences will influence spatial definitions and its elements, and determine rhythms and speeds of the experience (see Merriman 2010 on the work of landscape architect Lawrence Halprin).

Main difficulties in implementing the method in the context of the design process would be associated with the necessary time to prepare and run the walks as well as analysing the great amount of data produced within the tight timetables that design practices are subject of. 
Finally, the method can be used by practitioners themselves to interrogate the landscape subject to the design. Walking and talking and, eventually, drawing, during their fieldwork is a way to engage with, immerse in, and observe with conscious attention (van Etteger 2016)

the environment. This direct experience contributes to support their expertise and to develop narrative practices that organize sequences and allow the understanding of materials and landscape processes (Potteiger \& Purinton 1998).

\section{Conclusion}

In this paper we have been trying to demonstrate that the self-narrated walk is an effective method to capture mobile and in-the-moment experiences and perceptions of places and their associated meanings and values. This is a method that gives voice to users (Larkin et al. 2006; Ward Thompson et al. 2010) while facilitating to be in close contact with places and nature in order to offer an inside, user-led, perspective (Merleau-Ponty 1995; Berleant 2004; Berleant 2010; Heft 2010).

The self-narrated walk emphasises the use of mobile techniques and narratives that express the detail of meaning (Coles et al. 2013; Costa et al. 2014). The method embraces a multi data set approach to extend the breadth and range of inquiry (Greene et al. 1989; Johnson et al. 2007) and gathers, in real-time, spatial, visual, verbal and non-verbal representations in order to produce in-depth and comprehensive narratives of personal experiences of places. Contrary to other indoor or static methods, this technique provides an opportunity to target specific types of interaction or associations, to identify the deep meaning of such and to make comparisons between individuals. It articulates the distinctive embodied interactions between self and landscape (Wylie 2005) as entangled entities that shape each other (Lund 2012), in particular, the haptic interactions and bodily movements, the spatial sensory qualities and associated sensory response, the consciousness of environmental positive and negative intrusions, the appreciation for certain place characteristics, memory associations, and silences.

The self-narrated walk enables the open study of others' experiences avoiding predetermined questions that emphasise researchers' presumptions, many times present in other walking methods (e.g. walk-along interviews), bias and direct intervention that may occur whilst walking alongside. Thus, it empowers participants and their involvement in the research process broadened by being in control of the equipment, movements and time, and the freedom of choosing the aspects to share. A key and distinctive aspect lies on the fact that the 
method emphasises real-time, aloud, account of the experience which may reveal details that arise from the in-the-moment spatial and emotional consciousness.

\section{References}

Adler, P.A. \& Adler, P., 2001. The Reluctant Respondent. In Handbook of Interview Research. Thousand Oaks, CA: SAGE Research Methods, pp. 515-535.

Anderson, J., 2004. Talking whilst walking: a geographical archaeology of knowledge. Area, 36(3), pp.254-261.

Andresen, T., 2011. Serralves Park. In T. Andresen, M. Fernandes de Sá, \& J. Almeida, eds. Jacques Gréber: Urbanista e Arquitecto de Jardins. Urbanist and Garden Designer. Porto: Fundação de Serralves, pp. 24-55.

Ballard, P., 1983. Oasis of Delight: The History of the Birmingham Botanical Gardens, Gerald Duckworth \& Co Ltd.

Bannon, F., 2011. Synchronising Self and City: An Everyday Aesthetic for Walking. In R. Coles \& Z. K. Millman, eds. Landscape, well-being and Environment. Routledge, pp. $38-52$.

Van den Berg, A., Koole, S. \& Vanderwulp, N., 2003. Environmental preference and restoration: (How) are they related? Journal of Environmental Psychology, 23(2), pp.135-146.

Van den Berg, A.E., 2003. Personal need for structure and environmental preference. In L. Hendrickx, W. Jager, \& L. Steg, eds. Human decision making and environmental perception: understanding and assisting human decision making in real-life settings. Liber Amicorum for Charles Vlek. Groningen: Rijksuniversiteit Groningen: University of Groningen. Available at: http://www.narcis.nl/publication/RecordID/oai:library.wur.nl:wurpubs/327895 [Accessed December 16, 2012].

Berleant, A., 2010. Sensibility and Sense: The Aesthetic Transformation of the Human World. The British Journal of Aesthetics, p.230.

Berleant, A., 2004. The aesthetics of art and nature. In A. Carlson \& A. Berleant, eds. The Aesthetics of Natural Environments. Ontario: Broadview Press, pp. 76-88.

Berleant, A., 1992. The Aesthetics of Environment:, Philadelphia: Temple University Press. 
Berleant, A., 2012. The Changing Meaning of Landscape. In International Conference: Transition Landscapes/ Paysages en Transition. Lisbon, pp. 1-13. Available at: filarqpais.fl.ul.pt/index_ficheiros/Berleant_2012.pdf.

Carpiano, R.M., 2009. Come take a walk with me: the "go-along" interview as a novel method for studying the implications of place for health and well-being. Health \& place, 15(1), pp.263-72.

Carroll, P. et al., 2013. Kids in the city: differing perceptions of neighbourhood in Aotearoa/New Zealand. In R. Coles \& Z. Millman, eds. Landscape, Well-Being and Environment. London: Routledge, pp. 129-146.

Clandinin, D.J. \& Connelly, F.M., 2000. Narrative Inquiry: Experience and Story in Qualitative Research. Narrative Inquiry, 2, p.211.

Coles, R. \& Bussey, S.C., 2000. Urban forest landscapes in the UK — progressing the social agenda. Landscape and Urban Planning, 52(2-3), pp.181-188.

Coles, R. \& Caserio, M., 2004. Understanding and Facilitating the Social Outputs of Urban Green Spaces. In Conference “Open Space, People Space.” Edinburgh: OPENSpace. Available at: http://www.openspace.eca.ac.uk/conference/proceedings/PDF/Coles1.pdf [Accessed December 9, 2013].

Coles, R., Millman, Z.K. \& Flannigan, J., 2013. Urban landscapes - everyday environmental encounters, their meaning and importance for the individual. Urban Ecosystems, 16(4), pp.819-839.

Costa, S., 2015. The Choreography of Landscape Experience. Person-Place Interactions in Selected Environments. Birmingham City University.

Costa, S., Coles, R. \& Boultwood, A., 2015. Landscape Experience and the Speed of Walking. In G. Niin \& H. Mishra, eds. Landscapes in Flux. Tartu: Eesti Maaülikool, pp. $124-128$.

Costa, S., Coles, R. \& Boultwood, A., 2014. Walking Narratives: Interacting Between Urban Nature and Self. In C. Sörensen \& K. Liedtke, eds. SPECIFICS: Discussing Landscape Architecture. Jovis, pp. 40-43.

Craig, T., Conniff, A. \& Galan-Diaz, C., 2012. The Influences of Actual and Perceived Familiarity on Environmental Preferences for the Design of a Proposed Urban Square. Urban Studies Research, 2012, pp.1-9. 
Degen, M.M. \& Rose, G., 2012. The Sensory Experiencing of Urban Design: The Role of Walking and Perceptual Memory. Urban Studies, 49(15), pp.3271-3287.

Edensor, T., 2000. Walking in the British Countryside: Reflexivity, Embodied Practices and Ways to Escape. Body \& Society, 6(3-4), pp.81-106.

van Etteger, R., 2016. Beyond the visible : prolegomenon to an aesthetics of designed landscapes. Wageningen University. Available at: http://library.wur.nl/WebQuery/clc/2182646.

Evans, J. \& Jones, P., 2011. The walking interview: Methodology, mobility and place. Applied Geography, 31(2), pp.849-858.

Evenson, K.R. et al., 2006. Girls' perception of physical environmental factors and transportation: reliability and association with physical activity and active transport to school. The international journal of behavioral nutrition and physical activity, 3(1), p.28.

Foxley, A. \& Vogt, G., 2010. Distance and Engagement. Walking, Thinking and Making Landscape. VOGT landscape architects, Baden: Lars Muller Publishers.

Greene, J.C., Caracelli, V.J. \& Graham, W.F., 1989. Toward a Conceptual Framework for Mixed-Method Evaluation Designs. Educational Evaluation and Policy Analysis, 11(3), pp. $255-274$.

Hartig, T. et al., 2003. Tracking restoration in natural and urban field settings. Journal of Environmental Psychology, 23(2), pp.109-123.

Hartig, T. \& Staats, H., 2004. Linking preference for environments with their restorative quality. In Proceedings of the Frontis Workshop From Landscape Research to Landscape Planning Aspects of Integration Education and Application Wageningen The Netherlands 16 June 2004. Available at: http://library.wur.nl/frontis/landscape_research/19_hartig.pdf.

Heft, H., 2010. Affordances and the perception of landscape: an inquiry into environmental perception and aesthetics. In C. W. Thompson, P. Aspinall, \& S. Bell, eds. Innovative approaches to researching landscape and health - Open space: People space 2. New York: Routledge, pp. 11-32.

Herzog, T., Chen, H. \& Primeau, J., 2002. Perception of the restorative potential of natural and other settings. Journal of environmental psychology, 22, pp.295-306. 
Ingold, T., 2008. Bindings against boundaries: entanglements of life in an open world. Environment and Planning A, 40, pp.1796-1811.

Ingold, T., 2004. Culture on the Ground: The World Perceived Through the Feet. Journal of Material Culture, 9(3), pp.315-340.

Ingold, T. \& Vergunst, J.L., 2008. Introduction to Ways of Walking. In T. Ingold \& J. L. Vergunst, eds. Ways of Walking Ethnography and Practice on Foot. Ashgate, pp. 1-19.

Johnson, R.B., Onwuegbuzie, A.J. \& Turner, L.A., 2007. Toward a Definition of Mixed Methods Research. Journal of Mixed Methods Research, 1(2), pp.112-133.

Jones, P.I., Bunce, G. \& Evans, J., 2008. Exploring space and place with walking interviews. Journal of Research Practice, 4(2), p.Article-D2.

Kaplan, R. \& Kaplan, S., 1989. The experience of nature: a psychological perspective First., Cambridge University Press.

Kusenbach, M., 2003. Street Phenomenology: The Go-Along as Ethnographic Research Tool, Larkin, M., Watts, S. \& Clifton, E., 2006. Giving voice and making sense in interpretative phenomenological analysis. Qualitative Research in Psychology, 3(2), pp.102-120.

Latham, A., 2004. Researching and writing everyday accounts of the city: an introduction to the diary-photo diary-interview method. In C. Knowles \& P. Sweetman, eds. Picturing the Social Landscape. Routledge, pp. 117-131.

Leach, N., 2005. Rethinking architecture: a reader in cultural theory Reprinted. N. Leach, ed., London and New York: Routledge.

Lund, K., 2012. Landscapes and Narratives: Compositions and the Walking Body. Landscape Research, 37(2), pp.225-237.

Lund, K., 2005. Seeing in Motion and the Touching Eye: Walking over Scotland's Mountains R. Bendix \& D. Brenneis, eds. Etnofoor, 17(1), pp.27-42.

Merleau-Ponty, M., 1995. Phenomenology of perception (trans. C. Smith) 10th ed., New York: Routledge.

Merriman, P., 2010. Architecture/dance: choreographing and inhabiting spaces with Anna and Lawrence Halprin. Cultural Geographies, 17(4), pp.427-449.

Miaux, S. et al., 2010. Making the narrative walk-in-real-time methodology relevant for 
public health intervention: towards an integrative approach. Health \& place, 16(6), pp.1166-73.

Millman, Z.K., 2012. Landscape narratives and the construction of meaning in the contemporary urban canal-scape. Birmingham City University.

Millman, Z.K., 2013. Photographic Postcards as Research Tools: The "Postcards from the Cut” Study. Graduate Journal of Social Science, 10(2), pp.54-75.

Murray, M., 2003. Narrative Psychology and Narrative Analysis. In P. M. Camic, J. E. Rhodes, \& L. Yardley, eds. Qualitative research in psychology: Expanding perspectives in methodology and design. Washington, DC: American Psychological Association, pp. 95-112.

Nielsen, T. \& Hovgesen, H.H., 2004. Walk21-V Cities for People, The Fifth International Conference on Walking in the 21 st Century. In GPS in pedestrian and spatial behaviour surveys. Copenhagen, Denmark, pp. 1-13. Available at: http://vbn.aau.dk/fbspretrieve/3559564/TSN_HHH_Cities_for_people_2004.pdf [Accessed May 30, 2011].

Petiteau, J., 2006. La méthode des itinéraires ou la mémoire involontaire. In A. Berque, A. De Biase, \& P. Bonnin, eds. Habiter dans sa poétique première. Cerisy-La-Salle, France: Editions Donner Lieu. Available at: https://halshs.archivesouvertes.fr/file/index/docid/380133/filename/2006_JY_P_COL_MethodeItinerairesMe moireInvolontaire.pdf [Accessed February 20, 2017].

Pink, S., 2007. Walking with video. Visual Studies, 22(3), pp.240-252.

Pink, S. \& Mackley, K.L., 2012. Video and a Sense of the Invisible: Approaching Domestic Energy Consumption Through the Sensory Home. Sociological Research Online, 17 (1)(3), pp.1-16.

Potteiger, M. \& Purinton, J., 1998. Landscape Narratives: design practices for telling stories, John Wiley and Sons.

Riley, R.B., 1998. Experience and Time in the Work of Bernard Lassus. In B. Lassus, ed. The Landscape Approach. University of Pensylvania Press.

Rose, G., 2014. On the Relation between "Visual Research Methods" and Contemporary Visual Culture. The Sociological Review, 62(1), pp.24-46. 
Schroeder, H.W., 2002. Experiencing Nature in Special Places: Surveys in the North-Central Region. Journal of Forestry, 100(5), p.7.

Seamon, D., 2000. A Way of Seeing People and Place: Phenomenology in EnvironmentBehavior Research. Theoretical Perspectives in Environment-Behavior Research, pp.157-178.

Shah, S., 2004. The researcher/interviewer in intercultural context: a social intruder! British Educational Research Journal, 30(4), pp.549-575.

Smith, D.W., 2011. Phenomenology. The Stanford Encyclopedia of Philosophy, Fall. Available at: http://plato.stanford.edu/archives/fall2011/entries/phenomenology/ [Accessed November 6, 2013].

VanderStoep, S.W. \& Johnston, D.D., 2009. Research methods for everyday life: blending qualitative and quantitative approaches, Jossey-Bass, John Wiley \& Sons.

Visser, F.S. et al., 2005. Contextmapping: experiences from practice. CoDesign, 1(2), pp.119-149.

Ward Thompson, C. et al., 2010. Landscape quality and quality of life. In C. W. Thompson, P. Aspinall, \& S. Bell, eds. Innovative approaches to researching landscape and healthOpen space: People space 2. Abingdon: Rroutledge, pp. 230-255.

Wiles, J.L., Rosenberg, M.W. \& Kearns, R.A., 2005. Narrative analysis as a strategy for understanding interview talk in geographic research. Area, 37(1), pp.89-99.

Willig, C., 2001. Introducing qualitative research in psychology Adventures in theory and method, Philadelphia: Open University Press.

Wunderlich, F.M., 2008. Walking and Rhythmicity: Sensing Urban Space. Journal of Urban Design, 13(1), pp.125-139.

Wylie, J., 2005. A single day's walking: narrating self and landscape on the South West Coast Path. Transactions of the Institute of British Geographers, 30(2), pp.234-247.

Figure 1. Extract of a diagram showing different data sets collected through the self-narrated walk: voice transcript, GPS information and photos. The diagram is composed of: 1 . Place the sequence of places where the interaction and the narrative occurs; 2 . The photos taken by the participant; 3 . The voice transcript, including moments of silence; 4. Participant's speed 
profile; 5 . The narrative timeline - the duration of the walk and associated events, including time spent in each place. The diagram also offers a tool for analysis allowing the addition of more layers of data as the analysis progresses.

Figure 2. Participants' walking movements at the Birmingham Botanical Gardens.

Figure 3. Participant photograph of her interaction with the place whilst recalling and reconstructing a previous experience associated with 'running small leaves down the water' and 'stepping stones'.

Figure 4. Sensitive plant 